\title{
Potential treatment of COVID-19 by inhibitors of human dihydroorotate dehydrogenase
}

\author{
Yechun $\mathrm{Xu}^{1,2}$, Hualiang Jiang ${ }^{1,2,3 凶}$ \\ ${ }^{1}$ CAS Key Laboratory of Receptor Research, Shanghai Institute of Materia Medica, Chinese Academy of Sciences, Shanghai \\ 201203, China \\ 2 University of Chinese Academy of Sciences, Beijing 100049, China \\ ${ }^{3}$ Shanghai Institute for Advanced Immunochemical Studies and School of Life Science and Technology, ShanghaiTech \\ University, Shanghai 201210, China \\ $\bowtie$ Correspondence: hljiang@simm.ac.cn (H. Jiang)
}

The ongoing pandemic of severe acute respiratory syndrome coronavirus 2 (SARS-CoV-2), referred to as coronavirus disease 2019 (COVID-19), has caused over 13 million infections and over 560,000 deaths worldwide (https://www. who.int/emergencies/diseases/novel-coronavirus-2019/sit uation-reports), posing a significant threat to globally public health and economics. At present, no efficacious antiviral drugs and vaccines have been approved for the prophylaxis or treatment of COVID-19. Tremendous efforts have been made to develop drug and vaccine against SARS-CoV-2. The main protease (Mpro, also called 3CLpro) is an attractive drug target among coronaviruses, and several potent inhibitors of the SARS-CoV-2 3CLpro together with their crystal structures in complex with the protease have been reported (Dai et al., 2020; Jin et al., 2020; Zhang et al., 2020). While the viral RNA-dependent RNA polymerases $(\mathrm{RdRp})$ are well-known broad-spectrum antiviral drug targets, the cryo-electron microscopy structures of the SARSCoV-2 RdRp and its complex with remdesivir, a promising antiviral candidate developed by Gilead Sciences, validated the efficient inhibition of the viral RNA replication by remdesivir and provided a rational template for drug design to combat SARS-CoV-2 infections (Gao et al., 2020; Wang et al., 2020; Yin et al., 2020). In addition, the trimeric spike protein on the surface of SARS-CoV-2 plays a pivotal role during the viral entry by binding to the peptidase domain of angiotensin-converting enzyme 2 (ACE2), a host cell receptor (Yan et al., 2020). It has been revealed that not only the receptor binding domain which is recognized by ACE2 but also the N-terminal domain of the SARS-CoV-2 spike protein is targeting sites for therapeutic monoclonal antibodies (Chi et al., 2020). Accordingly, both the inhibitors of 3CLpro or RdRp and the antibodies targeting the spike protein provide potential candidates for development of the direct-acting antiviral (DAA) drugs for the treatment of COVID-19.
In addition to DAA drugs, host-targeting antiviral (HTA) agents, targeting host proteins required for the viral infection and replication, have advantages in overcoming drug resistance and combating a broad spectrum of viruses including the newly emerging virus ( $\mathrm{Ji}$ and $\mathrm{Li}, 2020$ ). Maraviroc, an antagonist of chemokine receptor type 5 for HIV treatment, presents a typical HTA drug. In a remarkable study published in this journal, Xiong et al. reported novel and potent inhibitors of human dihydroorotate dehydrogenase (DHODH) as broad-spectrum antiviral agents against RNA viruses including SARS-CoV-2 (Xiong et al., 2020).

Pyrimidines serve as crucial building blocks for the biosynthesis of DNA, RNA, phospholipids, and glycoproteins, which is essential for the cell survival as well as proliferation (Loffler et al., 2005). Human DHODH belongs to the class $2 \mathrm{DHODH}$ family and is a flavin-dependent mitochondrial enzyme catalyzing the oxidation of dihydroorotate to orotate, the fourth step also a rate limiting step in the de novo biosynthesis of pyrimidine-based nucleotides (Reis et al., 2017) (Fig. 1A). By consequence, DHODH is an attractive therapeutic target for multiple diseases including cancer and autoimmune diseases (Lolli et al., 2018; Boschi et al., 2019; Madak et al., 2019). Leflunomide and its metabolite teriflunomide, and brequinar are well-known DHODH inhibitors and were evaluated in clinical trials (Lolli et al., 2018). Leflunomide was approved for the therapy of rheumatoid arthritis many years ago (Herrmann et al., 2000).

With a computer-aided hit discovery and optimization strategy, Xiong et al. identified two novel and potent inhibitors of DHODH with a thiazole scaffold, S312 and S416 (Diao et al., 2012; Li et al., 2015; Zhu et al., 2015). The $I C_{50}$ S of these two compounds against human $\mathrm{DHODH}$ were 29.2 and $7.5 \mathrm{nmol} / \mathrm{L}$, respectively, $\mathrm{a}>10$-fold increase in activity relative to the FDA-approved teriflunomide $\left(\mathrm{IC}_{50}=307.1 \mathrm{nmol} / \mathrm{L}\right)$. The X-ray crystal structure of DHODH in complex with $\mathrm{S} 416$ also revealed the binding mode of two inhibitors at the ubiquinone- 


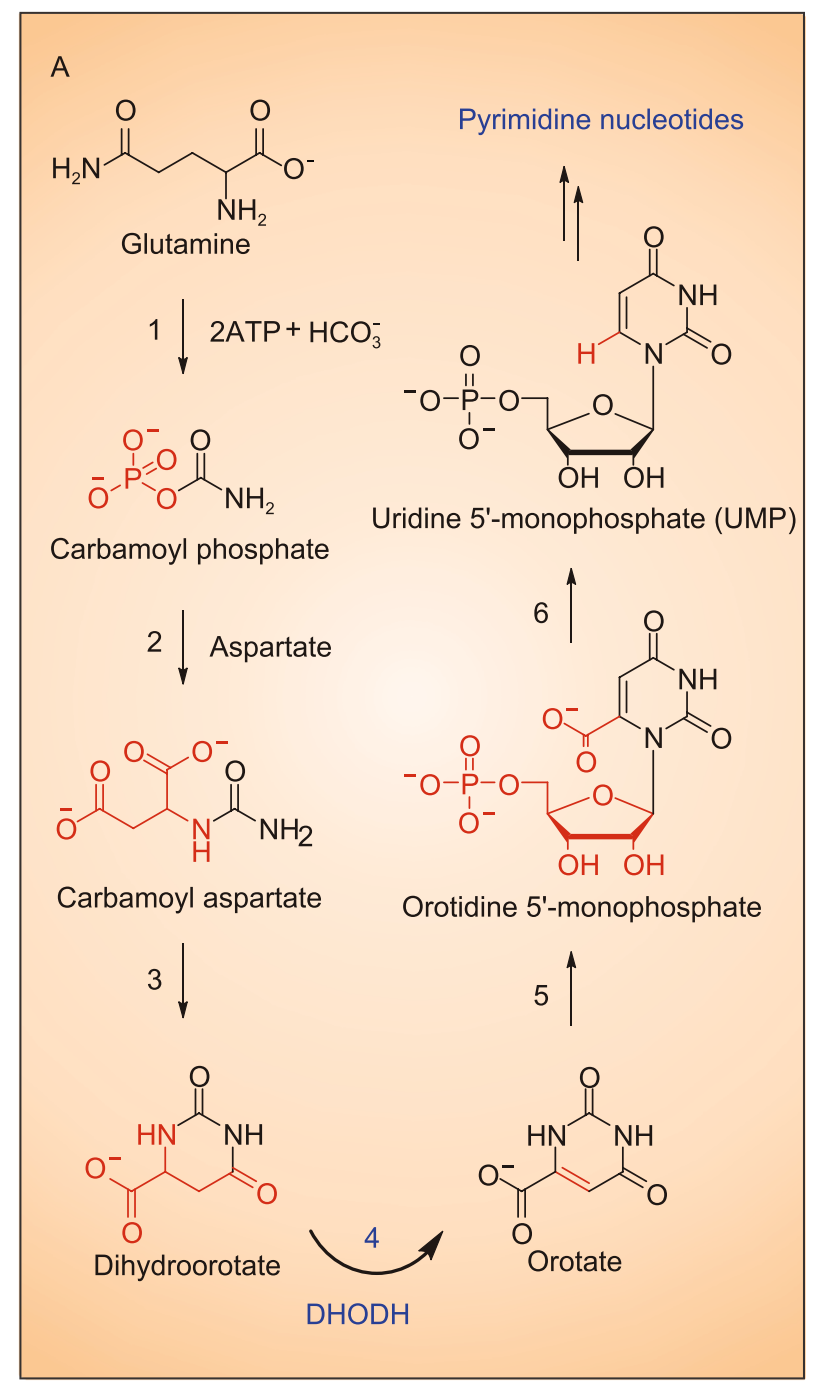

B

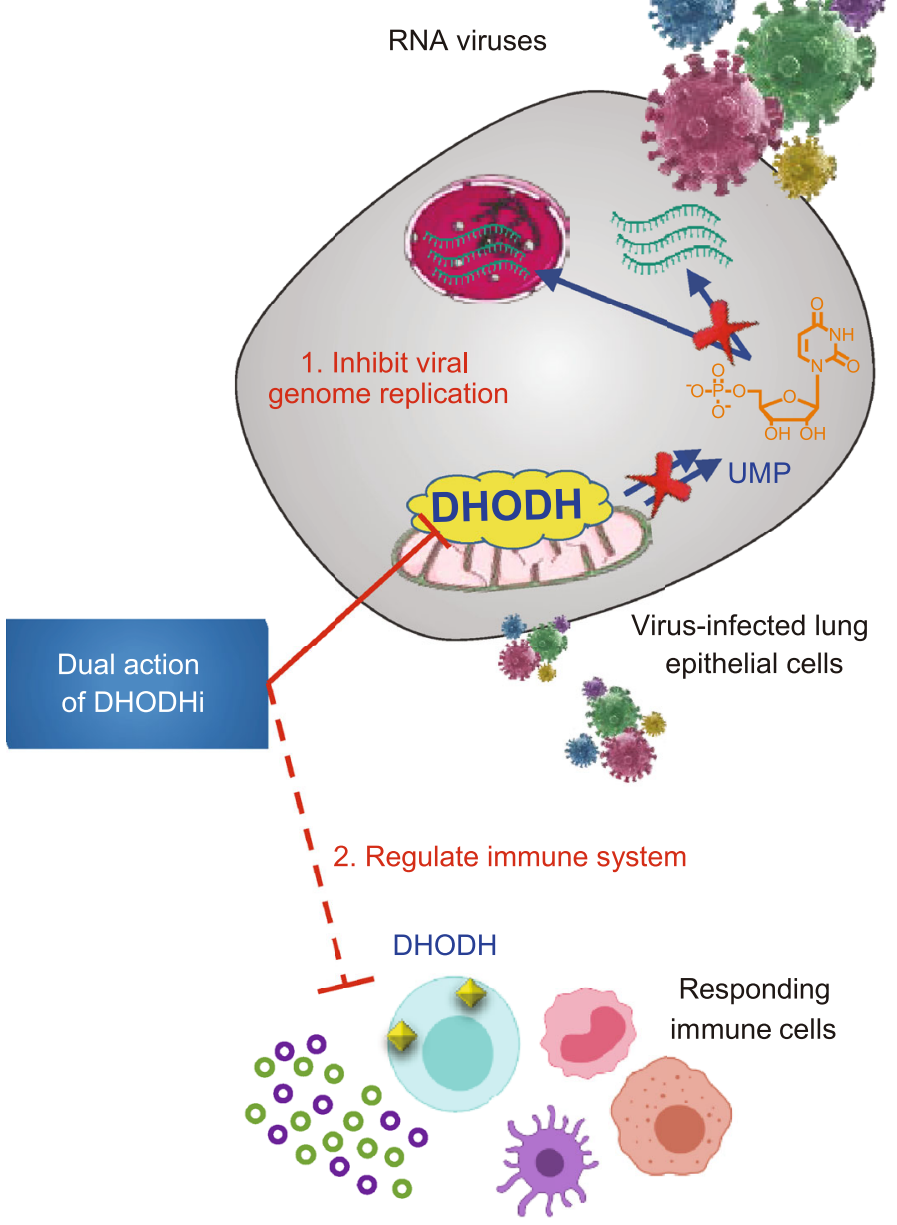

Cytokine storm

Figure 1. DHODH in the de novo pyrimidine biosynthesis pathway and dual action of DHODHi. (A) DHODH catalyzes the fourth step in the de novo pyrimidine biosynthesis pathway. (B) $\mathrm{DHODH}$ inhibitors (DHODHi) are broad-spectrum antivirals against RNA viruses with the dual action of inhibiting viral genome replication and regulating the immune system.

binding site of the enzyme. Moreover, two inhibitors exhibited significant antiviral activities against influenza A ( $\mathrm{H} 1 \mathrm{~N} 1, \mathrm{H} 3 \mathrm{~N} 2$ and H9N2), Zika, Ebola, and SARS-CoV-2 in cells infected with various tested viruses, demonstrating that $\mathrm{DHODH}$ inhibitors possess broad-spectrum antiviral activity by interfering the de novo pyrimidine synthesis pathway. Low toxicities of the inhibitors suggest that the reduced production of pyrimidine restricts virus replication but not cell growth. Most notably, the $\mathrm{EC}_{50}$ of $\mathrm{S} 416$ against the viral replication in the cells infected with SARS-CoV-2 at MOI of 0.05 is $17 \mathrm{nmol} / \mathrm{L}$, and the resulting selectivity index $\left(\mathrm{SI}=\mathrm{CC}_{50} / \mathrm{EC}_{50}\right)$ reaches 10505.88 . It is much more potent than that of teriflunomide or brequinar and is also by far the most effective inhibitor against SARS-CoV-2 in cells.
Another striking feature of this work is that S312 exhibited in vivo anti-influenza efficacy equivalent to that of oseltamivir, a marketed drug for the treatment of influenza. S312 at a dose of $5 \mathrm{mg} / \mathrm{kg}$ was also able to rescue all the influenzainfected mice from body weight loss and death. By contrast, previous studies often showed that inhibitors of either DHODH or the de novo pyrimidine biosynthesis pathway were ineffective against infection in animal models. In addition, the combination administration of S312 and oseltamivir resulted in $100 \%$ protection of the infected mice, superior to the single use of S312 or oseltamivir. S312 was also effective in the mice infected with an oseltamivir-resistant virus and had a remarkable advantage over oseltamivir to treat the late phase of the infectious disease. These results together demonstrated the feasibility of DHODH inhibitors used as 
efficacious antivirals as well as the combination of the DHODH inhibitor with DAA to overcome drug resistance.

As leflunomide and teriflunomide are used to treat autoimmune diseases such as rheumatoid arthritis and multiple sclerosis by regulating lymphocytes and the release of cytokines and chemokines, it is reasonable to conjecture that S312 and S416 would have the similar efficacy too. As anticipated, the combination use of $\mathrm{S} 312$ and oseltamivir significantly reduced the levels of IL-6, MCP-1, IL-5, KC/ GRO (CXCL1), IL-2, IFN-y, IP-10, IL-9, TNF- $\alpha$, GM-CSF, EPO, IL-12p70, MIP-3 $\alpha$, and IL-17A/F in the animal model. Therefore, the DHODH inhibitors not only inhibit the viral replication but also have regulatory roles in cytokine/chemokine production. Cytokine storm frequently occurred with patients suffered from virus infections such as SARS-CoV and SARS-CoV-2, antiviral treatment alone is thereby not enough and should be combined with appropriate anti-inflammatory treatment. The DHODH inhibitors provide the ideal candidate to take both into consideration.

Taken together, this elegant work uncovers that $\mathrm{DHODH}$ is an attractive host target for developing broad-spectrum antivirals which achieve the efficacy through dual mechanism of action of antiviral and immuno-regulation (Fig. 1B), providing more therapeutic options in response to COVID-19 as well as other emergent RNA virus infections. In the present situation, S312 and S416, two potent inhibitors of $\mathrm{DHODH}$ with favorable drug-likeness and pharmacokinetic profiles, serve as right HTAs for further evaluation of therapeutic potential in COVID-19 treatment. Meanwhile, as a new concept for the treatment of COVID-19, the clinical trial of leflunomide has been initiated in England and founded by LifeArc (DEFEAT-COVID study) (https://www.lifearc.org/ funding/covid-19-funding/).

\section{COMPLIANCE WITH ETHICS GUIDELINES}

The authors declare no conflict of interest. This article does not contain any studies with human or animal subjects performed by the author.

\section{OPEN ACCESS}

This article is licensed under a Creative Commons Attribution 4.0 International License, which permits use, sharing, adaptation, distribution and reproduction in any medium or format, as long as you give appropriate credit to the original author(s) and the source, provide a link to the Creative Commons licence, and indicate if changes were made. The images or other third party material in this article are included in the article's Creative Commons licence, unless indicated otherwise in a credit line to the material. If material is not included in the article's Creative Commons licence and your intended use is not permitted by statutory regulation or exceeds the permitted use, you will need to obtain permission directly from the copyright holder. To view a copy of this licence, visit http:// creativecommons.org/licenses/by/4.0/.

\section{REFERENCES}

Boschi D, Pippione AC, Sainas S, Lolli ML (2019) Dihydroorotate dehydrogenase inhibitors in anti-infective drug research. Eur $\mathrm{J}$ Med Chem 183:111681

Chi X, Yan R, Zhang J, Zhang G, Zhang Y, Hao M, Zhang Z, Fan P, Dong $Y$, Yang $Y$ et al (2020) A neutralizing human antibody binds to the N-terminal domain of the Spike protein of SARS-CoV-2. Science. https://doi.org/10.1126/science.abc6952

Dai W, Zhang B, Jiang XM, Su H, Li J, Zhao Y, Xie X, Jin Z, Peng J, Liu $F$ et al (2020) Structure-based design of antiviral drug candidates targeting the SARS-CoV-2 main protease. Science 368:1331-1335

Diao Y, Lu W, Jin H, Zhu J, Han L, Xu M, Gao R, Shen X, Zhao Z, Liu $X$ et al (2012) Discovery of diverse human dihydroorotate dehydrogenase inhibitors as immunosuppressive agents by structure-based virtual screening. J Med Chem 55:8341-8349

Gao Y, Yan L, Huang Y, Liu F, Zhao Y, Cao L, Wang T, Sun Q, Ming $Z$, Zhang $L$ et al (2020) Structure of the RNA-dependent RNA polymerase from COVID-19 virus. Science 368:779-782

Herrmann ML, Schleyerbach R, Kirschbaum BJ (2000) Leflunomide: an immunomodulatory drug for the treatment of rheumatoid arthritis and other autoimmune diseases. Immunopharmacology 47:273-289

Ji X, Li Z (2020) Medicinal chemistry strategies toward host targeting antiviral agents. Med Res Rev. https://doi.org/10.1002/med. 21664

Jin Z, Du X, Xu Y, Deng Y, Liu M, Zhao Y, Zhang B, Li X, Zhang L, Peng $C$ et al (2020) Structure of $M^{\text {pro }}$ from SARS-CoV-2 and discovery of its inhibitors. Nature 582:289-293

Li S, Luan G, Ren X, Song W, Xu L, Xu M, Zhu J, Dong D, Diao Y, Liu $X$ et al (2015) Rational design of benzylidenehydrazinylsubstituted thiazole derivatives as potent inhibitors of human dihydroorotate dehydrogenase with in vivo anti-arthritic activity. Sci Rep 5:14836

Loffler M, Fairbanks LD, Zameitat E, Marinaki AM, Simmonds HA (2005) Pyrimidine pathways in health and disease. Trends Mol Med 11:430-437

Lolli ML, Sainas S, Pippione AC, Giorgis M, Boschi D, Dosio F (2018) Use of human dihydroorotate dehydrogenase $(\mathrm{hDHODH})$ inhibitors in autoimmune diseases and new perspectives in cancer therapy. Recent Pat Anticancer Drug Discov 13:86-105

Madak JT, Bankhead A 3rd, Cuthbertson CR, Showalter HD, Neamati N (2019) Revisiting the role of dihydroorotate dehydrogenase as a therapeutic target for cancer. Pharmacol Ther 195:111-131

Reis RAG, Calil FA, Feliciano PR, Pinheiro MP, Nonato MC (2017) The dihydroorotate dehydrogenases: past and present. Arch Biochem Biophys 632:175-191

Wang M, Cao R, Zhang L, Yang X, Liu J, Xu M, Shi Z, Hu Z, Zhong W, Xiao G (2020) Remdesivir and chloroquine effectively inhibit the recently emerged novel coronavirus (2019-nCoV) in vitro. Cell Res 30:269-271

Xiong R, Zhang L, Li S, Sun Y, Ding M, Wang Y, Zhao Y, Wu Y, Shang $W$, Jiang $X$ et al (2020) Novel and potent inhibitors targeting $\mathrm{DHODH}$ are broad-spectrum antivirals against RNA 
viruses including newly-emerged coronavirus SARS-CoV-2. Protein Cell. https://doi.org/10.1007/s13238-020-00768-w

Yan R, Zhang Y, Li Y, Xia L, Guo Y, Zhou Q (2020) Structural basis for the recognition of SARS-CoV-2 by full-length human ACE2. Science 367:1444-1448

Yin W, Mao C, Luan X, Shen DD, Shen Q, Su H, Wang X, Zhou F, Zhao W, Gao M et al (2020) Structural basis for inhibition of the RNA-dependent RNA polymerase from SARS-CoV-2 by remdesivir. Science 368:1499-1504
Zhang L, Lin D, Sun X, Curth U, Drosten C, Sauerhering L, Becker S, Rox K, Hilgenfeld R (2020) Crystal structure of SARS-CoV-2 main protease provides a basis for design of improved alphaketoamide inhibitors. Science 368:409-412

Zhu J, Han L, Diao Y, Ren X, Xu M, Xu L, Li S, Li Q, Dong D, Huang $J$ et al (2015) Design, synthesis, X-ray crystallographic analysis, and biological evaluation of thiazole derivatives as potent and selective inhibitors of human dihydroorotate dehydrogenase. J Med Chem 58:1123-1139 